\title{
1 Air pollution control efficacy and health 2 impacts: A global observed study from 2000 to 2016
}

Chunlei Han ${ }^{1,2}$, Rongbin $\mathrm{Xu}^{2}$, Yajuan $\mathrm{Zhang}^{3}$, Wenhua $\mathrm{Yu}^{2}$, Shanshan $\mathrm{Li}^{2}$, Zhongwen Zhang $^{1}$,Lidia Morawska ${ }^{4}$, Jane Heyworth ${ }^{5}$, Bin Jalaludin ${ }^{6}$, Geoffrey Morgan ${ }^{7}$, Guy Marks $^{8}$, Michael Abramson ${ }^{2}$, Liwei Sun ${ }^{1}$, and Yuming Guo ${ }^{1,2}$ *

1 School of Public Health and Management, Binzhou Medical University, Yantai, Shandong, China 2 Department of Epidemiology and Preventive Medicine, School of Public Health and Preventive Medicine, Monash University, Melbourne, Australia

3 School of Public Health and Management, Ningxia Medical University, Yinchuan, Ningxia Hui Autonomous Region, China

4 International Laboratory for Air Quality and Health, Brisbane, Queensland University of Technology, Queensland, Australia; \& Science and Engineering Faculty, Queensland University of Technology, Brisbane, Queensland, Australia

5 School of Population and Global Health, The University of Western Australia, Crawley, Western Australia, Australia

6 School of Public Health and Community Medicine, The University of New South Wales, Kensington, 2052, Australia

7 Faculty of Medicine and Health, Sydney School of Public Health, The University of Sydney, Sydney, NSW 2006, Australia

8 South Western Sydney Clinical School UNSW, Sydney, New South Wales, Australia

* Corresponding author: Yuming Guo, Yuming.Guo@monash.edu.

\begin{abstract}
Background: $\mathrm{PM}_{2.5}$ concentrations vary between countries with similar $\mathrm{CO}_{2}$ emissions, possibly due to differences in air pollution control efficacy. However, no indicator of the level of air pollution control efficacy has yet been developed. We aimed to develop such an indicator, and to evaluate its global and temporal distribution and its association with country-level health metrics.

Method: A novel indicator, ground level population-weighted average $\mathrm{PM}_{2.5}$ concentration per unit $\mathrm{CO}_{2}$ emission per capita $\left(P M_{2.5} / \mathrm{CO}_{2}\right.$, written as $\mathrm{PC}$ in abbreviation $)$, was developed to assess countryspecific air pollution control efficacy. We estimated and mapped the global average distribution of $\mathrm{PC}$ and PC changes during 2000-2016 across 196 countries. Pearson correlation coefficients and Generalized Additive Mixed Model (GAMM) were used to evaluate the relationship between PC and health metrics.

Results: PC varied by country with an inverse association with the economic development. PC showed an almost stable trend globally from 2000 to 2016 with the low income groups increased. The Pearson correlation coefficients between PC and life expectancy at birth (LE), Infant-mortality rate (IMR), Under-five mortality rate (U5MR) and logarithm of GDP per capita (LPGDP) were $-0.566,0.646$, $0.659,-0.585$ respectively (all P-values $<0.001$ ). Compared with $\mathrm{PM}_{2.5}$ or $\mathrm{CO}_{2}, \mathrm{PC}$ could explain more variation of LE, IMR and U5MR. The association between PC and health metrics was independent of GDP per capita.

Conclusions: PC might be a good indicator for air pollution control efficacy and was related to important health indicators. Our findings provide a new way to interpret health inequity across the globe from the point of air pollution control efficacy.
\end{abstract}

Keywords:air pollution, climate change, health inequity, air pollution control efficacy

NOTE: This preprint reports new research that has not been certified by peer review and should not be used to guide clinical practice. 


\section{Introduction}

Ambient air pollution is a major public health concern. Among all ambient air pollutants, the particulate matter with aerodynamic diameter $\leq 2.5 \mathrm{um}\left(\mathrm{PM}_{2.5}\right)$ is the most important one that poses significant adverse health impacts in both short-term and long-term[1,2]. At the same time, carbon dioxide $\left(\mathrm{CO}_{2}\right)$ emissions have increased rapidly along with the rapid growth of economic development requiring more energy for transportation and energy consumption. As both ground level $\mathrm{PM}_{2.5}$ and $\mathrm{CO}_{2}$ are mainly caused by fossil-fuel combustion [3], there might be a relationship between $\mathrm{CO}_{2}$ emission and ground level $\mathrm{PM}_{2.5}$ concentration [4]. Studies conclude that actions to reduce greenhouse gas emissions often lead to co-benefits for air quality [5]. But interestingly, ground level $\mathrm{PM}_{2.5}$ concentrations are quite different across countries with similar $\mathrm{CO}_{2}$ emissions [4]. Many low- and middle-income countries (LMICs) face the dual pressure of reducing both ground level $\mathrm{PM}_{2.5}$ concentrations and $\mathrm{CO}_{2}$ emissions[5], while high income countries (HICs) have much lower ground level $\mathrm{PM}_{2.5}$ concentrations despite their high greenhouse gas emissions[6]. In other words, economically developed countries generally have lower ground level $\mathrm{PM}_{2.5}$ concentrations and relatively good air quality compared with economically developing countries, despite their similar or even higher $\mathrm{CO}_{2}$ emissions[7]. This fact suggests that different countries have different abilities to control ambient air pollution, even with similar $\mathrm{CO}_{2}$ emissions. An indicator to reflect the air pollution control efficacy may provide important information for policymakers, in order to achieve climate and air quality co-benefits and help guide environmental policy development and implementation [8].

The combustion sources of ground level $\mathrm{PM}_{2.5}$ concentrations are different across countries. Ground level $\mathrm{PM}_{2.5}$ concentrations are substantially from residential energy use such as heating and cooking in China, India, Bangladesh, Indonesia, Vietnam and Nepal; from traffic in Germany, the UK and the USA; from power generation in the USA, Russia, Korea, Turkey and the Middle East; from agriculture in Europe, Russia, Turkey, Korea, Japan and the Eastern USA[9]. Energy structure and environmental technology are both determinants of air pollution control efficacy. Environmental technological progress can enhance energy efficiency, thereby leading to reductions in ground level $\mathrm{PM}_{2.5}$ concentrations [4,10]. Developed countries may have more economic foundation to promote and apply technological innovation to reduce both $\mathrm{CO}_{2}$ emission and ground level $\mathrm{PM}_{2.5}$ concentration compared with developing countries. In developed countries such as North America and Europe, technological improvements in scrubbers on power plants, catalytic converters on motor vehicles, and increased development of non-fossil fuel based energy sources have reduced ground level $\mathrm{PM}_{2.5}$ concentrations [11]. Although emission reduction technologies play a role in improving air quality in economically developing countries like China [12], not all effective strategies are adopted due to the high $\operatorname{cost}[13]$.

Cleaner air due to air pollution reduction will improve human health[13]. Correspondingly, inequality in air pollution control efficacy contributes to human health inequality between countries[14]. An indicator of air pollution control efficacy could help identify the ground level air pollution concentration co-benefits of reducing emissions of $\mathrm{CO}_{2}$ [15]. The quantitative relationship between the air pollution control efficacy indicator and human health might provide important guidance for policymakers to reduce the disease burden due to ambient air pollution globally [4].

Currently, there is no indicator to reflect country level air pollution control efficacy. To fill the research gap, we aim to evaluate a potential novel indicator of air pollution control efficacy, by quantifying its global distribution and long-term trend, and by examining its relationship with health indicators. Monitoring such an indicator may assist policy makers to better manage climate change and air pollution problems simultaneously [5].

\section{Materials and methods}

\subsection{Indicator}

To capture air pollution control efficacy with $\mathrm{CO}_{2}$ emission, we proposed a novel indicator, ground level population weighted $\mathrm{PM}_{2.5}$ concentration per unit $\mathrm{CO}_{2}$ emission per capita (PC). A lower $\mathrm{PC}$ value generally indicates a higher air pollution control efficiency, meaning lower concentration of 
ground level $\mathrm{PM}_{2.5}$ with per unit of $\mathrm{CO}_{2}$ emission. The unit of $\mathrm{PC}$ is $\mu \mathrm{g} / \mathrm{m}^{3}$ per tonne. $\mathrm{PC}$ is calculated as follows:

$$
P C_{i, t}=P M_{2.5} \text { i,t } / \mathrm{CO}_{2 i, t}
$$

Here, i means the $\mathrm{i}^{\text {th }}$ country or region, $\mathrm{t}$ means the $\mathrm{t}^{\text {th }}$ year.

\subsection{Data collection}

The spatial and temporal domain of our study included 196 countries from 2000 and 2016. Some regions like Greenland, Antarctica and some countries in Middle Africa were not included in the spatial map because of the missing data.

To develop the novel indicator of air pollution control efficacy, population-weighted ground level $\mathrm{PM}_{2.5}\left(\mathrm{PM}_{2.5}, \mu \mathrm{g} / \mathrm{m}^{3}\right)$ and annual emissions of carbon dioxide per capita $\left(\mathrm{CO}_{2}\right.$, tonne) for individual countries based on territorial $\mathrm{CO}_{2}$ emissions were sourced from the atmospheric composition analysis group, Global Carbon Project, Carbon Dioxide Information Analysis Centre (CDIAC), Gapminder and UN population estimates(see supplement for more details). $\mathrm{PM}_{2.5}$ in each country was represented by the population density weighted average value of all grids within the boundary of the country[16]. We transformed the original spatial resolution of this population density dataset into $0.1^{\circ} \times 0.1^{\circ}$ resolution according to the method described by Brauer et al[17].

To evaluate the association between PC and health, we collected data on several health outcomes. The first one is life expectancy at birth (LE, years), defined as the average number of years that a newborn could expect to live if he or she were to pass through life subject to the age-specific mortality rates of a given period. Children are more affected by air pollution and climate change $[3,18]$. It was reported that per $10 \mu \mathrm{g} / \mathrm{m}^{3}$ increases in $\mathrm{PM}_{2.5}$ concentration was related to $3.4 \%$ (95\% CI: $1.7 \%-5.4 \%$ ) infant and child under-five mortality[19]. Therefore,we included the health outcomes of infantmortality rate (IMR, \%) and under-five mortality rate (U5MR, \%), which mean the number of infants dying before reaching one year of age and the number of babies that died before reaching age five per 1,000 live births in a given year. We obtained data of LE, IMR, U5MR from various sources including the United Nations (UN) Population Division, World Bank(WB), UN Inter-agency Group for Child Mortality Estimation, World Health Organization (WHO) (see supplement for more details).

Temperature and humidity are related to health [20] and country-level annual average Temperature at 2 meters $\left(\mathrm{T} 2 \mathrm{M},{ }^{\circ} \mathrm{C}\right)$ and Specific Humidity at 2 Meters $(\mathrm{QV} 2 \mathrm{M}, \mathrm{g}$ water/kg dry air, $\mathrm{g}$ kg-1) were obtained from the National Aeronautics and Space Administration (NASA) (see supplement in details). GDP per capita (PGDP, U.S.\$) in constant 2010 U.S. dollars came from WB and the Organization for Economic Co-operation and Development (OECD) (see supplement for more details).

\subsection{Statistical Methods}

Correlations between each two independent variables were examined by Pearson correlation coefficient. The Generalized Additive Mixed Model (GAMM) with a penalized spline smoothing function, a random intercept of country and spatial covariance structure, and a Gaussian link function, was used to evaluate the potential non-linear relationship between PC and health outcomes [21,22].

To ensure the results' robustness, we excluded 5\% observations with extreme large and small PC and kept the remaining $95 \%$ data in the middle for analyses. The model performance was expressed as adjusted $\mathrm{R}^{2}$. The GAMM was as following:

$$
H_{i, t}=\beta_{0}+s\left(P C_{i, t}\right)+s\left(D_{i, t}\right)+u_{i}
$$

Here $H$ represents the health outcome, which could be LE, IMR, or U5MR; i,t means the $i^{\text {th }}$ country( $\mathrm{i}=1$ to 196$)$ in the $\mathrm{t}^{\text {th }}(\mathrm{t}=2000$ to 2016$)$ year. $\beta_{0}$ denotes the constant intercept; $\mathrm{s}($.$) is the$ smoothing function realized by cubic spline with 4 degrees of freedom(df) in this study. $u_{i}$ is a random intercept for country i. D represents the covariates including PGDP, T2M, QV2M, PM $2.5, \mathrm{CO}_{2}$. The degrees of freedom (df) of the cubic spline function (CS) for each predictor was selected by minimizing the Akaike information criterion (AIC) of the model [23-25]. 
PC showed nonlinear correlation with health metrics as estimated in this paper, so here PC was modelled by a non-linear function. PGDP, T2M, QV2M were added to the models in the form of a natural cubic smooth function as their relationship with heath is often non-linear [26-28]. $\mathrm{PM}_{2.5}$ and $\mathrm{CO}_{2}$ were also included as covariates.

All statistical tests were two-sided, with a p-value of 0.05 as the indicator of the statistical significance. All analyses were performed using the R statistical software (version 3.2.2), including the R packages "ggplot2", "dplyr", "reldist" and "gamm4".

\section{Results}

\subsection{Descriptive results}

The means of $\mathrm{PM}_{2.5}$ and $\mathrm{CO}_{2}$ were $21.52\left(\mu \mathrm{g} / \mathrm{m}^{3}\right)$ and 4.60 (tonne) respectively. PC was 74.24 ( $\mu \mathrm{g} / \mathrm{m}^{3}$ per tonne) on average with the considerable international variance from $0.14\left(\mu \mathrm{g} / \mathrm{m}^{3}\right.$ per tonne) in Australia (2010) to $2659.75\left(\mu \mathrm{g} / \mathrm{m}^{3}\right.$ per tonne) in Chad (2002). The average LE, IMR and U5MR were 68.94 years, $2.97 \%$ and $4.27 \%$, respectively. PGDP was 15541.76 (U.S.\$) on average with a large range of 155795.00 (U.S.\$). As for average temperature and humidity, T2M was $18.33\left({ }^{\circ} \mathrm{C}\right)$ and QV2M10.03 $\left(\mathrm{g} \mathrm{kg}^{-1}\right)$ (see Table 1). Generally, PC was lowest in high income groups, and then uppermiddle income groups, lower-middle income groups, and highest in low income groups[29]. The mean, median, standard deviation and range of PC were increasing as the GDP per capita decreased (Table $\left.\mathrm{S}_{1}\right)$.

Table 1 Summary statistics of all variables in 196 countries between 2000 and 2016

\begin{tabular}{lllllllll}
\hline Variable & Unit & Mean & Sd & Min & $\mathbf{P}_{25}$ & $\mathbf{P}_{50}$ & $\mathbf{P}_{75}$ & Max \\
\hline PC & $\mu \mathrm{g} / \mathrm{m}^{3}$ per tonne & 74.24 & 207.37 & 0.14 & 1.96 & 4.59 & 34.62 & 2659.75 \\
$\mathrm{LE}$ & years & 68.94 & 9.30 & 38.70 & 62.97 & 71.47 & 75.62 & 83.80 \\
$\mathrm{IMR}$ & $\% 0$ & 2.97 & 2.72 & 0.16 & 0.79 & 1.95 & 4.62 & 14.20 \\
$\mathrm{U} 5 \mathrm{MR}$ & $\% 0$ & 4.27 & 4.48 & 0.21 & 0.83 & 2.35 & 6.70 & 23.39 \\
$\mathrm{PM}_{2.5}$ & $\mu \mathrm{g} / \mathrm{m}^{3}$ & 21.52 & 17.89 & 0.50 & 7.80 & 17.20 & 27.30 & 111.30 \\
$\mathrm{CO}_{2}$ & tonne & 4.60 & 6.41 & 0.02 & 0.55 & 2.23 & 6.35 & 66.81 \\
$\mathrm{PGDP}^{3}$ & $\mathrm{U} . S . \$$ & 15541.76 & 18191.91 & 349.00 & 2780.50 & 8651.00 & 22093.50 & 156144.00 \\
$\mathrm{~T} 2 \mathrm{M}$ & ${ }^{\circ} \mathrm{C}$ & 18.33 & 8.63 & -9.61 & 10.44 & 21.21 & 25.78 & 30.28 \\
$\mathrm{QV} 2 \mathrm{M}$ & $\mathrm{g} \mathrm{kg}$ & 10.03 & 4.67 & 2.59 & 6.05 & 8.76 & 14.49 & 19.28 \\
\hline
\end{tabular}

Notes: Sd: standard deviation; Min: minimum; $\mathrm{P}_{25}, \mathrm{P}_{50}, \mathrm{P}_{75}: 25^{\text {th }}, 50^{\text {th }}, 75^{\text {th }}$ percentile respectively; Max: maximum; $\mathrm{PC}: \mathrm{PM}_{2.5}$ concentration per unit per capita $\mathrm{CO}_{2}$ emission; LE: life expectancy at birth; IMR: Infant-mortality rate; U5MR: Under-five mortality rate; $\mathrm{PM}_{2.5}$ : fine particulate matter with aero dynamic diameter $\leq 2.5 \mathrm{um} ; \mathrm{CO}_{2}$ : carbon dioxide emission per capita; PGDP: GDP per capita; T2M: Temperatures at 2 meters; QV2M: Specific Humidity at 2 Meters.

\section{9}

\subsection{Spatial and temporal variation of $P C$}

The $\mathrm{PC}, \mathrm{PM}_{2.5}$ and $\mathrm{CO}_{2}$ trends of the whole world, different income groups (high, upper-middle, lower-middle, and low-income countries) and selected countries are shown in Figure 1. We selected two countries of the largest population in each income group to represent the corresponding income group. So we got 8 countries including the United States and Japan to represent the high income group; China and Brazil to stand for the upper-middle income group; India, Indonesia and Bangladesh, Nigeria to represent the lower-middle and low income group respectively.

Globally, the average PC remained almost stable from 2000 to 2016 worldwide. PC in low income 
medRxiv preprint doi: https://doi.org/10.1101/2020.05.31.20118752; this version posted June 1 , 2020. The copyright holder for this preprint (which was not certified by peer review) is the author/funder, who has granted medRxiv a license to display the preprint in perpetuity. All rights reserved. No reuse allowed without permission.

group showed an increased tendency while the upper-middle income group's PC decreased. Worldaverage $\mathrm{PM}_{2.5}$ increased with the most increment in lower-middle groups. $\mathrm{PM}_{2.5}$ in high income countries remained the least and kept almost flat. As for the annual average $\mathrm{CO}_{2}$ emission per capita trend, the world average increased by year. The high-income group took the largest part of $\mathrm{CO}_{2}$ emission. However, we could see the decreasing trend of $\mathrm{CO}_{2}$ in the high-income group. Meanwhile the low income group emitted the least and stable $\mathrm{CO}_{2} \cdot \mathrm{CO}_{2}$ emission of upper-middle and lowermiddle income groups increased from 2000 to 2016, too.

From 2000 to 2016, PC in Bangladesh decreased significantly (from $193.75 \mu \mathrm{g} / \mathrm{m}^{3}$ per tonne to $106.08 \mu \mathrm{g} / \mathrm{m}^{3}$ per tonne) while Nigeria increased (from $112.24 \mu \mathrm{g} / \mathrm{m}^{3}$ per tonne to $157.84 \mu \mathrm{g} / \mathrm{m}^{3}$ per tonne). By contrast, PC kept almost stable during the study period in the United States (from $0.53 \mu \mathrm{g} / \mathrm{m}^{3}$ per tonne to $0.46 \mu \mathrm{g} / \mathrm{m}^{3}$ per tonne) and Japan (from $1.40 \mu \mathrm{g} / \mathrm{m}^{3}$ per tonne to $1.47 \mu \mathrm{g} / \mathrm{m}^{3}$ per tonne). The similar increasing trend of $\mathrm{PM}_{2.5}$ concentration could be seen in most selected countries. While the two high income countries like the United States $\left(11.3 \mu \mathrm{g} / \mathrm{m}^{3}\right.$ in 2000 and $7.6 \mu \mathrm{g} / \mathrm{m}^{3}$ in 2016) and Japan $\left(13.9 \mu \mathrm{g} / \mathrm{m}^{3}\right.$ in both 2000 and 2016) showed decreasing or stable trend. The United States (21.28 and 16.48 tones per capita in 2000 and 2016) and Japan (9.90 and 9.43tones per capita in 2000 and 2016) are the largest two $\mathrm{CO}_{2}$ emission countries among the 8 countries while Bangladesh(from 0.21 to 0.52 tones per capita) and Nigeria(from 0.62 to 0.55 tones per capita ) the least.

(a) PC trend of different income groups

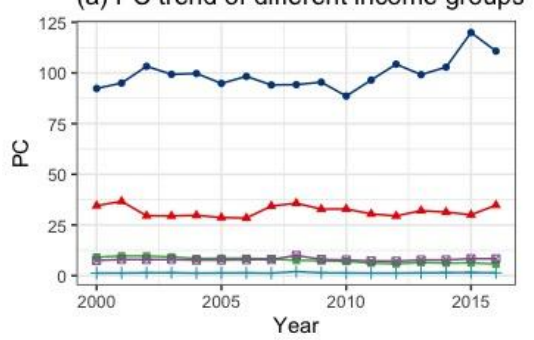

(c) PM2.5 trend of different income groups

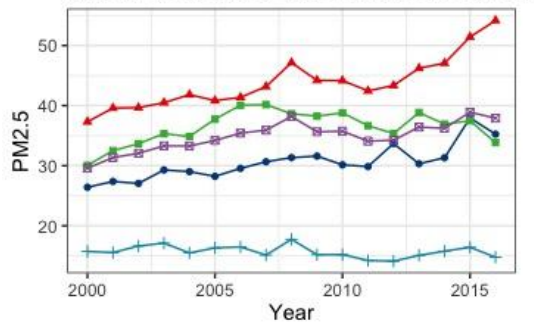

(e) $\mathrm{CO} 2$ trend of different income groups

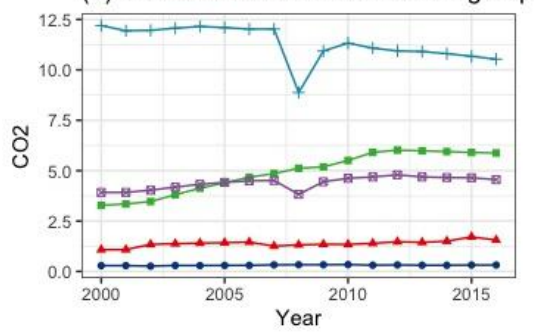

(b) PC trend of selected countries

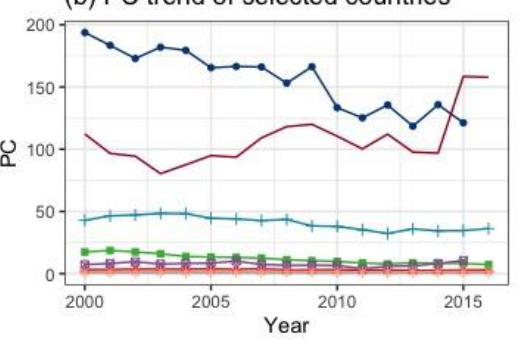

(d) PM2.5 trend of selected countries

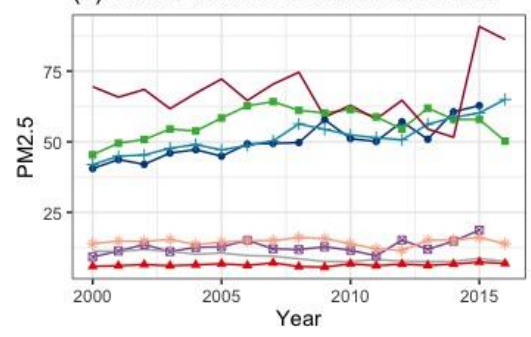

(f) $\mathrm{CO} 2$ trend of selected countries

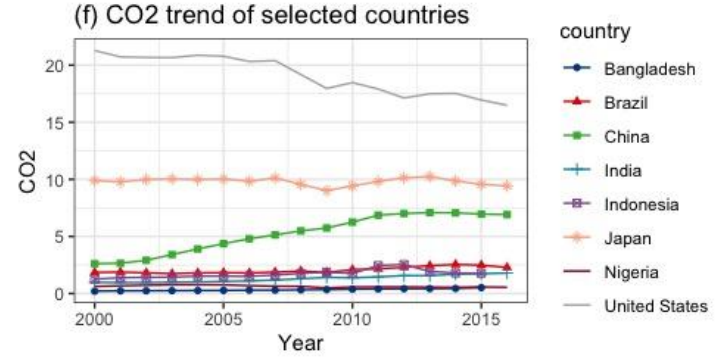

country

$\rightarrow$ Banglades

- Brazil

- China

+ India

\#- Indonesia

- Japan

- Nigeria

- United States

Income groups $\rightarrow$ low

$\downarrow$ lower-middle

- upper-middle

+ high

- world average

Income groups

$\rightarrow$ low

\ lower-middle

-- upper-middle

+ high

- world averag

Figure1. PC trends of the whole world, different income groups and selected countries

Notes: PC: $\mathrm{PM}_{2.5}$ concentration per unit per capita $\mathrm{CO}_{2}$ emission. We used population-weighted $\mathrm{PC}$, $\mathrm{PM}_{2.5}$ and $\mathrm{CO}_{2}$ to show time tendencies of different income groups. The units of $\mathrm{PC}, \mathrm{PM}_{2.5}$ and $\mathrm{CO}_{2}$ are $\mu \mathrm{g} / \mathrm{m}^{3}$ per tonne, $\mu \mathrm{g} / \mathrm{m}^{3}$ and tonne respectively.

The spatial distributions of PC during 2000 and 2016 are presented in Figure 2. In 2000, PCs in the countries like America, Europe, Australia and most countries in South America were lower than 5 $\left(\mu \mathrm{g} / \mathrm{m}^{3}\right.$ per tonne). In developing countries like China and India, PCs were higher than $10\left(\mu \mathrm{g} / \mathrm{m}^{3}\right.$ per tonne) but lower than $50\left(\mu \mathrm{g} / \mathrm{m}^{3}\right.$ per tonne). But in poor countries in Africa, most PCs were over 100 $\left(\mu \mathrm{g} / \mathrm{m}^{3}\right.$ per tonne). Specifically, PCs in Niger, Democratic Republic of Congo were over than 1000 $\left(\mu \mathrm{g} / \mathrm{m}^{3}\right.$ per tonne) and Chad over $2000\left(\mu \mathrm{g} / \mathrm{m}^{3}\right.$ per tonne). In 2016, PC almost showed the same spatial distribution globally. PC in China declined to $7.26\left(\mu \mathrm{g} / \mathrm{m}^{3}\right.$ per tonne) in 2016. PCs in Chad and Niger declined a lot but still over $1000\left(\mu \mathrm{g} / \mathrm{m}^{3}\right.$ per tonne). PCs in most countries of the world decreased in the past 17 years. The most remarkable decreases were observed for countries in Africa like Chad, 
medRxiv preprint doi: https://doi.org/10.1101/2020.05.31.20118752; this version posted June 1 , 2020. The copyright holder for this preprint (which was not certified by peer review) is the author/funder, who has granted medRxiv a license to display the preprint in perpetuity.

All rights reserved. No reuse allowed without permission.

Democratic Republic of Congo and Niger, then China and India. Meanwhile, some African countries suffered the PC growth, such as Somalia, Eritrea and Nigeria.
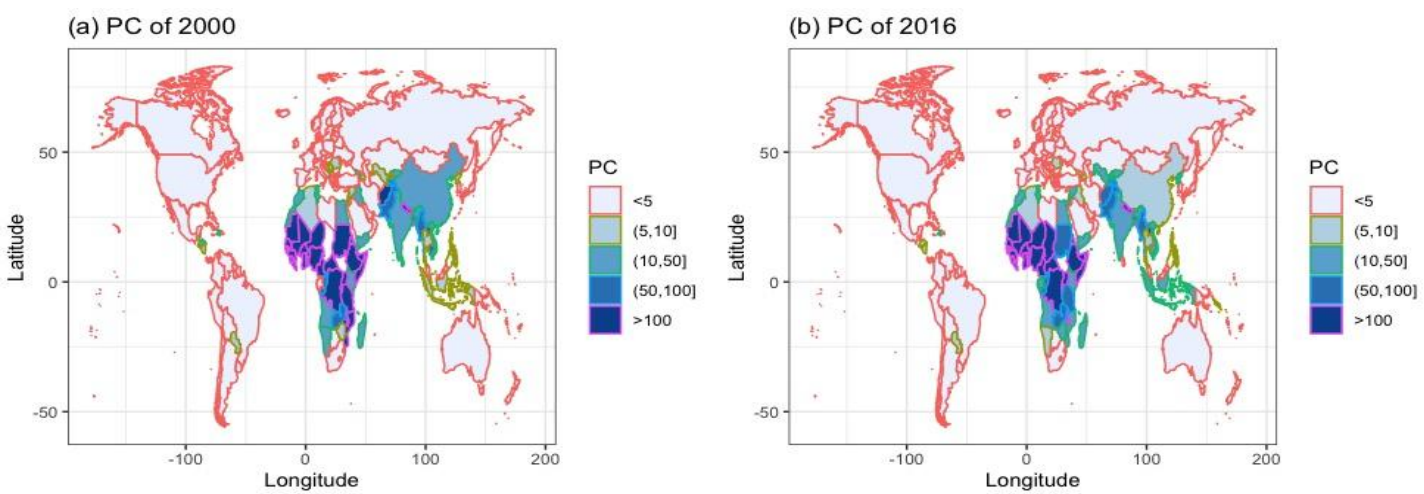

(c) Annual change in PC from 2000 to 2016

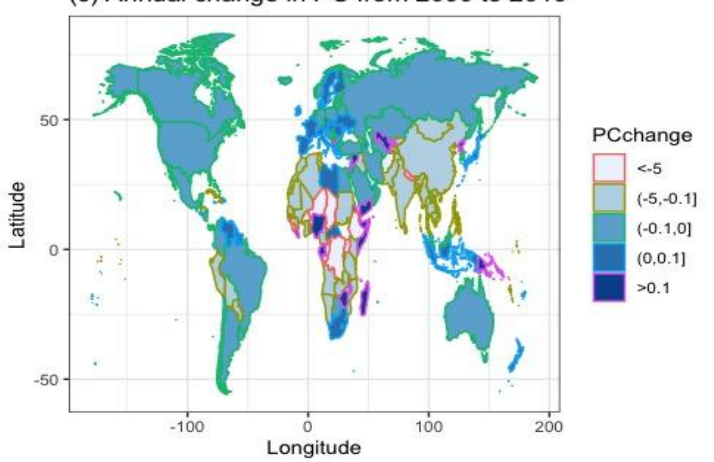

Figure 2. Country-level PC and annual average change in PC from 2000 to 2016

Notes: PC: $\mathrm{PM}_{2.5}$ concentration per unit per capita $\mathrm{CO}_{2}$ emission. The unit of $\mathrm{PC}$ is $\mu \mathrm{g} / \mathrm{m}^{3}$ per tonne.

\subsection{The relationship between $P C$ and health metrics}

The Pearson correlation coefficients between PC and LE, IMR, U5MR and LPGDP were -0.566, $0.646,0.659,-0.585$ respectively (Table $\mathrm{S}_{2}$ ), and all coefficients were statistically significant at the level of 0.001. Using GAMM, we investigated seven models to estimate the relation between PC and health (Table $\mathrm{S}_{3}$ ). In model with $\mathrm{PC}$ as the only independent variable, the adj. $\mathrm{R}^{2}$ were $0.320,0.417$ and 0.435 indicating PC independently explained $32.0 \%, 41.7 \%$ and $43.5 \%$ of the variation of LE, IMR and U5MR respectively. While in model with $\mathrm{PM}_{2.5}$ or $\mathrm{CO}_{2}$ as the only independent variable, $\mathrm{PM}_{2.5}$ and $\mathrm{CO}_{2}$ could only explain $3.45 \%, 7.81 \%, 10.49 \%$ and $22.11 \%, 22.39 \%, 19.84 \%$ of the respective variations of LE, IMR and U5MR. Therefore, PC seemed to be a better indicator to reflect health compared with $\mathrm{PM}_{2.5}$ and $\mathrm{CO}_{2}$. PGDP single could reflect variation of LE, IMR and U5MR by 58.0\%, $63.6 \%, 61.3 \%$ respectively.

We examined the nonlinear associations of PC with LE, IMR, U5MR and LPGDP in Figure 3 using GAMM. We got the reverse relation curves between PC and LE, LPGDP. Simultaneously, we found a positive relation between $\mathrm{PC}$ and IMR, U5MR. The non-linear relationships changed minimally when we altered the covariates of the model (Figure $\mathrm{S}_{1}$ ). 
(a) The association between PC and LE

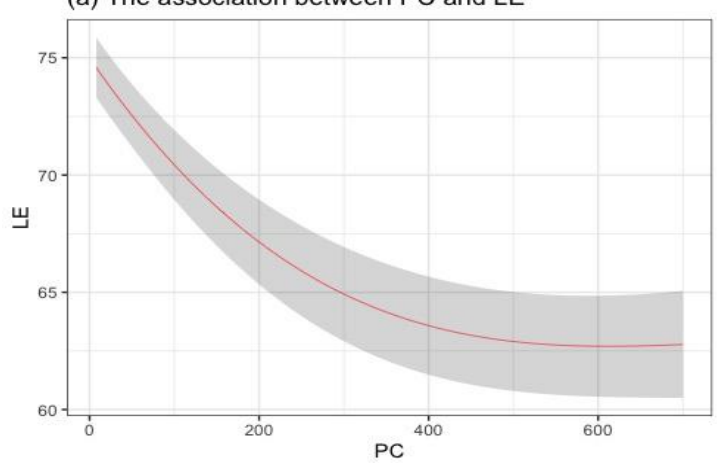

(c) The association between PC and U5MR

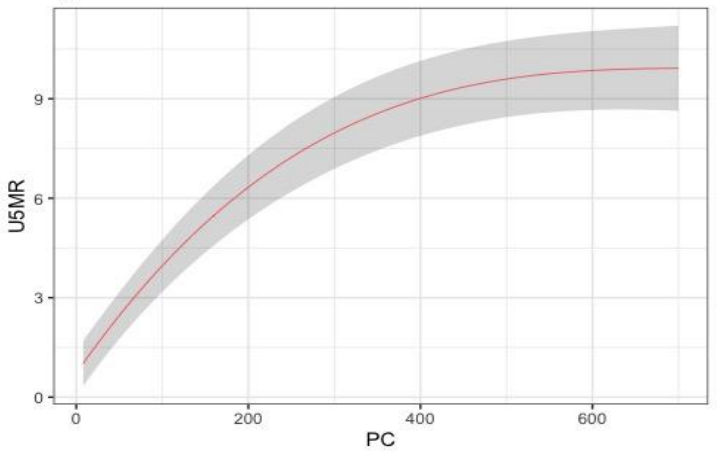

(b) The association between PC and IMR

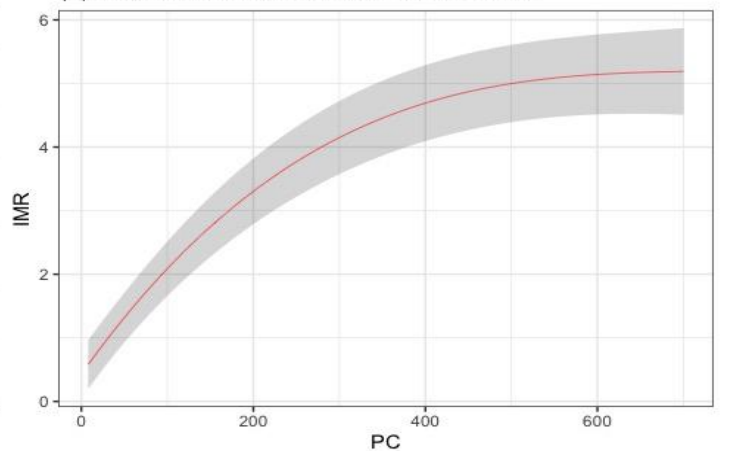

(d) The association between LPGDP and PC

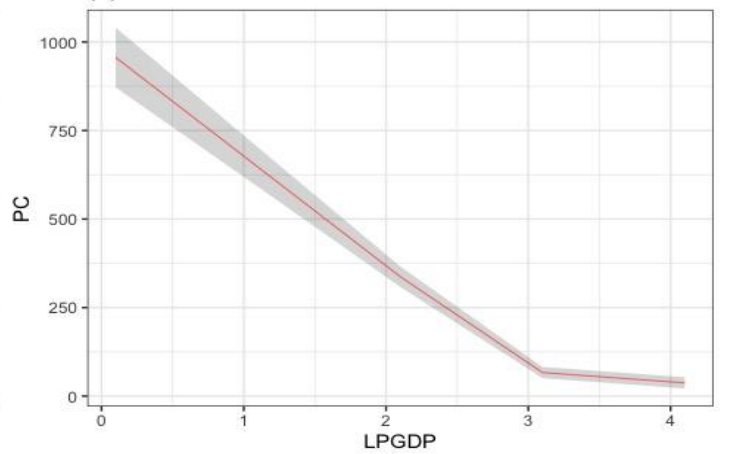

Figure 3. The modeled associations of PC with LE, IMR, U5MR and PGDP, by GAMM

Notes: Black shadow indicates 95\% confidence interval (CI). LE: life expectancy at birth, IMR: Infantmortality rate, U5MR: Under-five mortality rate, $\mathrm{PC}: \mathrm{PM}_{2.5}$ concentration per unit per capita $\mathrm{CO}_{2}$ emission, LPGDP: logarithm of GDP per capita. The GAMMs were (a): $\mathrm{PC}+\mathrm{PGDP}+\mathrm{T} 2 \mathrm{M}+\mathrm{QV} 2 \mathrm{M}+\mathrm{PM}_{2.5}+\mathrm{CO}_{2}$; (b): $\mathrm{PC}+\mathrm{PGDP}+\mathrm{T} 2 \mathrm{M}+\mathrm{QV} 2 \mathrm{M}+\mathrm{PM}_{2.5}+\mathrm{CO}_{2} ;$ (c): $\mathrm{PC}+\mathrm{PGDP}+\mathrm{T} 2 \mathrm{M}+\mathrm{QV} 2 \mathrm{M}+\mathrm{PM}_{2.5}+\mathrm{CO}_{2}$; (d): LPGDP.

\section{Discussion}

To the best of our knowledge, this is the first paper to evaluate PC as a potential new indicator of air quality control efficacy. This indicator almost kept stable over 2000-2016 in the world. There is great spatial variation or inequality of PC among countries. On average, PC was high in Africa and low in America, Europe and Australia, while Asia was in the middle range during 2000-2016.

Generally, PC is decreasing as the GDP per capita grows. PC is smaller in high income or developed countries than in low income or developing countries, possibly because the use of cleanpolluting production technologies increases with economic development [30]. For high income countries, they have the least $\mathrm{PC}$ with the highest $\mathrm{CO}_{2}$ emission but lowest $\mathrm{PM}_{2.5}$ concentration. Both $\mathrm{PM}_{2.5}$ concentration and $\mathrm{CO}_{2}$ emission showed decreasing tendency from 2000 to 2016 , so there is a clear plateau for most high-income countries over the past years. Taking the United States as an example, since the 1970s the United States government has input \$25 billion per year to the improvement of ambient air quality[31]. Over half of the coal-fired capacity in the United States will be equipped with the air pollution control technologies including selective catalytic reduction, electrostatic precipitators, sorbent injection and flue gas desulfurization or other scrubber technologies by $2020[32]$.

PC in upper-middle income countries decreased with the increase of $\mathrm{CO}_{2}$ and relatively slow increase of $\mathrm{PM}_{2.5}$. From 2000 to 2016, the decreasing PC in upper-middle groups might be contributed by technological improvement and green production promotion[30]. As the largest population country in the world and the largest upper-middle income country, PC in China decreased significantly, from $17.39\left(\mu \mathrm{g} / \mathrm{m}^{3}\right.$ per tonne) to $7.26\left(\mu \mathrm{g} / \mathrm{m}^{3}\right.$ per tonne). As the largest coal-consuming country in the world[12], the Chinese government has implemented many air quality plans such as "Air Pollution Prevention and Control Action Plan" [33] and "Reformation and Upgrading Action Plan with ultra-low 
emissions (ULE) technologies" focusing on controlling emissions from coal consumption, which have dramatically reduced $\mathrm{PM}_{2.5}$ emissions from coalfired power plants [12]. Therefore, $\mathrm{PM}_{2.5}$ in China remained almost unchanged from $49.5 \mu \mathrm{g} / \mathrm{m}^{3}$ in 2000 to $50.2 \mu \mathrm{g} / \mathrm{m}^{3}$ in 2016 , although $\mathrm{CO}_{2}$ emission in China increased a lot from 2.61 tones per capita to 6.91 tones per capita.

Lower-middle income countries, most located in South Asia, PC remained almost no change from 2000 to 2016 because of both increment of $\mathrm{PM}_{2.5}$ and $\mathrm{CO}_{2}$. $\mathrm{PM}_{2.5}$ concentrations in South Asia mainly due to combustion emissions(solid fuels, power plants, agricultural and other open burning, industry and transportation)[34]. Taking India, the largest population country of lower-middle income and one of the highest polluted countries globally as an example [35], the major source of ambient particulate matter pollution is coal burning [36]. Although Indian government has launched several initiatives including improving technologies of coal power plants, energy-intensive industries in the past few years to reduce air pollution [37], which reduced PC in India from $42.85\left(\mu \mathrm{g} / \mathrm{m}^{3}\right.$ per tonne) to 36.20 ( $\mu \mathrm{g} / \mathrm{m}^{3}$ per tonne), $\mathrm{PM}_{2.5}$ increased from $44.9 \mu \mathrm{g} / \mathrm{m}^{3}$ to $65 \mu \mathrm{g} / \mathrm{m}^{3}$ with $\mathrm{CO}_{2}$ increased from 0.98 tones per capita to 1.80 tones per capita during 2000 and 2016.

Low income countries are just on the contrary to the high income ones, which had the highest $\mathrm{PM}_{2.5}$ concentration but lowest $\mathrm{CO}_{2}$ emission. $\mathrm{PM}_{2.5}$ increased while $\mathrm{CO}_{2}$ almost unchanged during 2000 to 2016, causing PC increased. The three largest PC located in the three African countries of Chad, Niger and the Democratic Republic of Congo. It is needed to mention that air pollution in Africa, such as countries in north (Niger, Egypt and Mauritania) and west (Cameroon, Nigeria and Burkina Faso) Africa and the Middle East (Saudi Arabia, Qatar and Kuwait), $\mathrm{PM}_{2.5}$ is typically composed of aeolian dust and vegetation fires[38,39]. Besides, $26 \%$ of 51 million people relied on biomass fuel, gas and paraffin for cooking and $41.2 \%$ for heating in the 2011 South African Census report, which will also cause the air pollution[40]. In South Africa, some policies have been promulgated such as the National Environmental Management Air Quality Act (2004) which defined the Minimum Emissions Standards for regulating gaseous and particulate emissions from industrial operations. In 2009, South Africa pledged a target of $\mathrm{CO}_{2}$ emissions reductions also reduced $\mathrm{PM}_{2.5}$ by switching away from an fossil fuels based economy[41]. PC in Chad decreased from $2286.39 \mu \mathrm{g} / \mathrm{m}^{3}$ per tonne in 2000 to $1163.79 \mu \mathrm{g} / \mathrm{m}^{3}$ per tonne in 2016 and Niger from $1496.35 \mu \mathrm{g} / \mathrm{m}^{3}$ per tonne to $1029.71 \mu \mathrm{g} / \mathrm{m}^{3}$ per tonne. But the PC reduction mainly depend on the increment of $\mathrm{PM}_{2.5}$ (from $48.2 \mu \mathrm{g} / \mathrm{m}^{3}$ to $58.7 \mu \mathrm{g} / \mathrm{m}^{3}$ in Chad and $91.3 \mu \mathrm{g} / \mathrm{m}^{3}$ to $111.3 \mu \mathrm{g} / \mathrm{m}^{3}$ in Niger) and more fast increasing speed of $\mathrm{CO}_{2}$ (from 0.02 tones per capita to 0.05 tones per capita, from 0.06 tones per capita to 0.11 tones per capita respectively). However, it is needed to mention that some African countries suffered the PC growth, such as Somalia, Eritrea and Nigeria. There is still a long way to go for low income countries to improve the air pollution control efficiency as part of development of economy.

PC might be a good indicator of health. $\mathrm{PM}_{2.5}$ attributed mortality of childhood in sub-Saharan Africa (such as Chad, Sudan, and Nigeria) and south Asia (such as India and Pakistan) contributes substantially to the global YLLs (Years of life lost) from ambient air pollution[38,39]. Meanwhile, most largest PC located in the above two areas. It was estimated that highest rate of childhood mortality due to air pollution especially $\mathrm{PM}_{2.5}$ was in Chad (located in sub-Saharan Africa) with the largest PC in the world (mean of PC from 2000 to 2016 was $1333.10 \mu \mathrm{g} / \mathrm{m}^{3}$ per tonne)[41]. In Chad, YLLs per capita due to exposure to $\mathrm{PM}_{2.5}$ in children younger than 5 years are 1000 times higher than in the United States(mean of PC from 2000 to 2016 was $0.48 \mu \mathrm{g} / \mathrm{m}^{3}$ per tonne)[39]. Meanwhile, PC might be a better indicator for monitoring national progress of addressing air pollution related health burden than $\mathrm{PM}_{2.5}[2,42]$ or $\mathrm{CO}_{2}$ for the better explaining variation of LE, IMR and U5MR.

Compared with previous literature about association between $\mathrm{PM}_{2.5}, \mathrm{CO}_{2}$ and health[4,7], our paper suggests that more attention should also be paid to the air quality control efficacy, in order to realize climate, air quality and health co-benefits. The air pollution control efficiency could be improved through change of energy structure (e.g., shift to cleaner energy) and technology innovations (e.g., electric vehicle) $[43,44]$. We found that the association between PC and health metrics was independent of GDP per capita. This suggests that clean air brought by reducing PC might generate health improvements independent of economic growth. This result also suggest that the global health 
inequity is not merely explained by income inequality, but also by the inequality in the ability to control ambient air pollution.

Our findings contribute to the area of air pollution, climate change and human health. Firstly, it is useful for policymakers to pay more attention to air pollution control efficacy when dealing with climate change by reducing carbon emission. Secondly, PC provides a new angle to understand the global health equity. The low health levels of low income countries might be partly because of the low efficacy to reduce the harm from ambient air pollution [37]. Thus for low income countries, the promotion of air pollution control efficacy should be included as an important part of economic development. Also, assistance from developed countries to undeveloped ones should include not only improving the economy but also technologies related to air pollution control efficacy. These suggest that we could improve health equity more effectively by paying more attention to air pollution control efficiency.

The study has some limitations. Firstly, we did not obtain data from every country in the world like other global analysis[26]. Our study did not cover the Greenland, Antarctica and some Middle Africa because of the missing data. But as few people live in these areas, we could provide a reference for the majority of population in the world [26]. Secondly, due to data unavailability, we did not include data on factors that might contribute to PC such as energy structure and technologies of processing air pollution emissions. Future studies with relevant data could give a detailed evaluation on these contributing factors. There are some weaknesses of the PC index. Firstly, it couldn't reflect the air pollution caused by the natural sources of aeolian dust and vegetation fires from the unpaved roads or deserts. Secondly, PC maybe not change while some improvements both happens in air pollution control and reducing $\mathrm{CO}_{2}$ per capita. That is why PC in high income countries keep stable from 2000 to 2016 as decrease happened in both $\mathrm{PM}_{2.5}$ concentration and $\mathrm{CO}_{2}$ emission. Thirdly, in theory PC would reduce if $\mathrm{CO}_{2}$ emission increases without impacting on ground level $\mathrm{PM}_{2.5}$ exposure within country. This is clearly not a good outcome to climate change and health. Anyway, PC is really a good indicator to reflect air pollution control efficiency because it reduces with changing the energy structure from coal to clean energy[33,35], improving air cleaning technology[10]. There are many ways to develop the PC indicator in the next stages. Other detailed covariates needed to be included like fossil fuel combustion emission control technology, unusual events like bushfire, natural sources and social disruptions.

\section{Conclusions}

In summary, our study developed a novel air pollution control efficacy indicator, ground level $\mathrm{PM}_{2.5}$ concentration per unit $\mathrm{CO}_{2}$ emission per capita (PC), to assess population air pollution exposure level related to carbon emission. The results indicated that PC has kept almost stable from 2000 to 2016 globally with the low income groups increased. PC is geographically different and getting lower with the economic development. PC is statistically associated with LE, IMR and U5MR, which provides a new way to promote global health equity from the angle air pollution control efficacy.

\section{Acknowledgements}

Some data were obtained from the NASA Langley Research Center POWER Project funded through the NASA Earth Science Directorate Applied Science Program. CH was supported by Shandong provincial department of education funded projects for overseas study; SL was supported by an Early Career Fellowship of the Australian National Health and Medical Research Council (number APP1109193); and YG was supported by Career Development Fellowships of the Australian National Health and Medical Research Council (numbers APP1163693).

\section{Data Availability Statement}

The data that support the findings of this study are available upon request from the authors.

\section{Declaration of competing interests}

The authors declare they have no actual or potential competing financial interests. 


\section{Funding}

This study was supported by Taishan Scholar Program.

\section{References}

[1] Ding, D., Xing, J., Wang, S., Liu, K. and Hao, J., 2019. Estimated contributions of emissions controls, meteorological factors, population growth, and changes in baseline mortality to reductions in ambient PM 2.5 and PM 2.5-related mortality in China, 2013-2017. Environmental health perspectives, 127(6), p.067009.

[2] Ouyang, W., Gao, B., Cheng, H., Hao, Z. and Wu, N., 2018. Exposure inequality assessment for PM2. 5 and the potential association with environmental health in Beijing. Science of the Total Environment, 635, pp.769-778.

[3] Perera, F., 2018. Pollution from fossil-fuel combustion is the leading environmental threat to global pediatric health and equity: Solutions exist. International journal of environmental research and public health, 15(1), p.16.

[4] Dong, F., Yu, B. and Pan, Y., 2019. Examining the synergistic effect of CO2 emissions on PM2. 5 emissions reduction: Evidence from China. Journal of cleaner production, 223, pp.759-771. mitigation for future air quality and human health. Nat Clim Change. 2013; 3: 885-9.

[6] Li, Z., Shao, S., Shi, X., Sun, Y. and Zhang, X., 2019. Structural transformation of manufacturing, natural resource dependence, and carbon emissions reduction: Evidence of a threshold effect from China. Journal of cleaner production, 206, pp.920-927.

[7] Anenberg, S.C., Achakulwisut, P., Brauer, M., Moran, D., Apte, J.S. and Henze, D.K., 2019. Particulate matter-attributable mortality and relationships with carbon dioxide in 250 urban areas worldwide. Scientific reports, $9(1)$, pp.1-6.

[8] Mao, X., Zhou, J. and Corsetti, G., 2014. How well have China's recent five-year plans been implemented for energy conservation and air pollution control?. Environmental science \& technology, 48(17), pp.10036-10044.

[9] Lelieveld, J., Evans, J.S., Fnais, M., Giannadaki, D. and Pozzer, A., 2015. The contribution of outdoor air pollution sources to premature mortality on a global scale. Nature, 525(7569), pp.367-371.

[10] He, C. and Wang, Z.L., 2018. Triboelectric nanogenerator as a new technology for effective PM2. 5 removing with zero ozone emission. Progress in Natural Science: Materials International, 28(2), pp.99-112.

[11] West, J.J., et al., 2016."What We Breathe Impacts Our Health: Improving Understanding of the Link between Air Pollution and Health". Environ Sci Technol, 50(10): p. 4895-904.

[12] Liu, X., Liu, Z., Jiao, W., Li, X., Lin, J. and Ku, A., 2017. Impact of "ultra low emission" technology of coalfired power on PM 2.5 pollution in the Jing-Jin-Ji Region. Frontiers in Energy, pp.1-5.

[13] Cao, J., Pui, D.Y., Kuehn, T.T., Tie, X., Ramachandran, G., Zhu, T., Wang, J. and Tao, W., 2014. 1st UMNCAS Bilateral Seminar on PM2. 5 science, health effects and control technology Xi'an, China, May 27-28, 2014. Particuology, 16, pp.227-229.

[14] Fong, H. and E. Harris, 2015. Technology, innovation and health equity. Bull World Health Organ, 93(7): p. 438-438A.

[15] Scovronick, N., Budolfson, M., Dennig, F., Errickson, F., Fleurbaey, M., Peng, W., Socolow, R.H., Spears, D. and Wagner, F., 2019. The impact of human health co-benefits on evaluations of global climate policy. Nature communications, 10(1), pp.1-12.

[16] Renzi, M., Forastiere, F., Schwartz, J., Davoli, M., Michelozzi, P. and Stafoggia, M., 2019. Long-Term PM 10 Exposure and Cause-Specific Mortality in the Latium Region (Italy): A Difference-in-Differences Approach. Environmental health perspectives, 127(6), p.067004.

[17] Brauer, M., Freedman, G., Frostad, J., Van Donkelaar, A., Martin, R.V., Dentener, F., Dingenen, R.V., Estep, K., Amini, H., Apte, J.S. and Balakrishnan, K., 2016. Ambient air pollution exposure estimation for the global burden of disease 2013. Environmental science \& technology, 50(1), pp.79-88.

[18] Yoon, C., Lee, K. and Park, D., 2011. Indoor air quality differences between urban and rural preschools in Korea. Environmental Science and Pollution Research, 18(3), pp.333-345.

[19] Karimi, B., 2020. Air pollution and mortality among infant and children under five years: a systematic review and meta-analysis. Atmospheric Pollution Research.

[20] Armstrong, B., Sera, F., Vicedo-Cabrera, A.M., Abrutzky, R., Åström, D.O., Bell, M.L., Chen, B.Y., de Sousa Zanotti Stagliorio Coelho, M., Correa, P.M., Dang, T.N. and Diaz, M.H., 2019. The Role of Humidity in Associations of High Temperature with Mortality: A Multicountry, Multicity Study. Environmental health perspectives, 127(9), p.097007.

[21] Jung, C.R., Hwang, B.F. and Chen, W.T., 2018. Incorporating long-term satellite-based aerosol optical depth, localized land use data, and meteorological variables to estimate ground-level PM2. 5 concentrations in Taiwan from 2005 to 2015. Environmental pollution, 237, pp.1000-1010.

[22] Owili, P.O., Lien, W.H., Muga, M.A. and Lin, T.H., 2017. The associations between types of ambient PM2. 5 and under-five and maternal mortality in Africa. International journal of environmental research and public 437 health, 14(4), p.359. 
[23] Chen, Z.Y., Zhang, T.H., Zhang, R., Zhu, Z.M., Ou, C.Q. and Guo, Y., 2018. Estimating PM2. 5 concentrations based on non-linear exposure-lag-response associations with aerosol optical depth and meteorological measures. Atmospheric Environment, 173, pp.30-37.

[24] Sorek-Hamer, M., Strawa, A.W., Chatfield, R.B., Esswein, R., Cohen, A. and Broday, D.M., 2013. Improved retrieval of PM2. 5 from satellite data products using non-linear methods. Environmental pollution, 182, pp.417423.

[25] Yang, J., Ou, C.Q., Ding, Y., Zhou, Y.X. and Chen, P.Y., 2012. Daily temperature and mortality: a study of distributed lag non-linear effect and effect modification in Guangzhou. Environmental Health, 11(1), p.63.

[26] Yin, Q., Wang, J., Ren, Z., Li, J. and Guo, Y., 2019. Mapping the increased minimum mortality temperatures in the context of global climate change. Nature communications, 10(1), pp.1-8.

[27] Gasparrini, A., Guo, Y., Hashizume, M., Lavigne, E., Zanobetti, A., Schwartz, J., Tobias, A., Tong, S., Rocklöv, J., Forsberg, B. and Leone, M., 2015. Mortality risk attributable to high and low ambient temperature: a multicountry observational study. The Lancet, 386(9991), pp.369-375.

[28] Li, T., Horton, R.M. and Kinney, P.L., 2013. Projections of seasonal patterns in temperature-related deaths for Manhattan, New York. Nature Climate Change, 3(8), pp.717-721.

[29] World Bank Data Team.New country classifications by income level: 2017-2018.July 1,2017. (https://blogs.worldbank.org/opendata/new-country-classifications-income-level-2017-2018)

(Accessed:12 May,2020)

[30] Ji, X., Yao, Y. and Long, X., 2018. What causes PM2. 5 pollution? Cross-economy empirical analysis from socioeconomic perspective. Energy Policy, 119, pp.458-472.

[31] Correia, A.W., Pope III, C.A., Dockery, D.W., Wang, Y., Ezzati, M. and Dominici, F., 2013. The effect of air pollution control on life expectancy in the United States: an analysis of 545 US counties for the period 2000 to 2007. Epidemiology (Cambridge, Mass.), 24(1), p.23.

[32] Thorneloe, S.A., Kosson, D.S., Sanchez, F., Garrabrants, A.C. and Helms, G., 2010. Evaluating the fate of metals in air pollution control residues from coal-fired power plants.

[33] Cai, S., Wang, Y., Zhao, B., Wang, S., Chang, X. and Hao, J., 2017. The impact of the "air pollution prevention and control action plan" on PM2. 5 concentrations in Jing-Jin-Ji region during 2012-2020. Science of the Total Environment, 580, pp.197-209.

[34] Shaddick, G., Thomas, M.L., Amini, H., Broday, D., Cohen, A., Frostad, J., Green, A., Gumy, S., Liu, Y., Martin, R.V. and Pruss-Ustun, A., 2018. Data integration for the assessment of population exposure to ambient air pollution for global burden of disease assessment. Environmental science \& technology, 52(16), pp.9069-9078.

[35] Cohen, A.J., Brauer, M., Burnett, R., Anderson, H.R., Frostad, J., Estep, K., Balakrishnan, K., Brunekreef, B., Dandona, L., Dandona, R. and Feigin, V., 2017. Estimates and 25-year trends of the global burden of disease attributable to ambient air pollution: an analysis of data from the Global Burden of Diseases Study 2015. The Lancet, 389(10082), pp.1907-1918.

[36] Upadhyay, A., Dey, S., Chowdhury, S. and Goyal, P., 2018. Expected health benefits from mitigation of emissions from major anthropogenic PM2. 5 sources in India: Statistics at state level. Environmental Pollution, 242, pp.1817-1826.

[37] Balakrishnan, K., Dey, S., Gupta, T., Dhaliwal, R.S., Brauer, M., Cohen, A.J., Stanaway, J.D., Beig, G., Joshi, T.K., Aggarwal, A.N. and Sabde, Y., 2019. The impact of air pollution on deaths, disease burden, and life expectancy across the states of India: the Global Burden of Disease Study 2017. The Lancet Planetary Health, 3(1), pp.e26-e39.

[38] Krotkov, N.A., McLinden, C.A., Li, C., Lamsal, L.N., Celarier, E.A., Marchenko, S.V., Swartz, W.H., Bucsela, E.J., Joiner, J., Duncan, B.N. and Boersma, K.F., 2015. Aura OMI observations of regional SO 2 and NO 2 pollution changes from 2005 to 2014. Atmospheric Chemistry \& Physics Discussions, 15(19).

[39] Lelieveld, J., Haines, A. and Pozzer, A., 2018. Age-dependent health risk from ambient air pollution: a modelling and data analysis of childhood mortality in middle-income and low-income countries. The lancet Planetary health, 2(7), pp.e292-e300.

[40] Shirinde, J., Wichmann, J. and Voyi, K., 2014. Association between wheeze and selected air pollution sources in an air pollution priority area in South Africa: a cross-sectional study. Environmental Health, 13(1), p.32.

[41] Henneman, L.R., Rafaj, P., Annegarn, H.J. and Klausbruckner, C., 2016. Assessing emissions levels and costs associated with climate and air pollution policies in South Africa. Energy Policy, 89, pp.160-170.

[42] Song, C., He, J., Wu, L., Jin, T., Chen, X., Li, R., Ren, P., Zhang, L. and Mao, H., 2017. Health burden attributable to ambient PM2. 5 in China. Environmental pollution, 223, pp.575-586.

[43]Zhang, Z., Shao, C., Guan, Y. and Xue, C., 2019. Socioeconomic factors and regional differences of PM2. 5 health risks in China. Journal of environmental management, 251, p.109564.

[44] Soubbotina, T.P., 2004. Beyond economic growth: An introduction to sustainable development. The World Bank. 
(a) PC of 2000

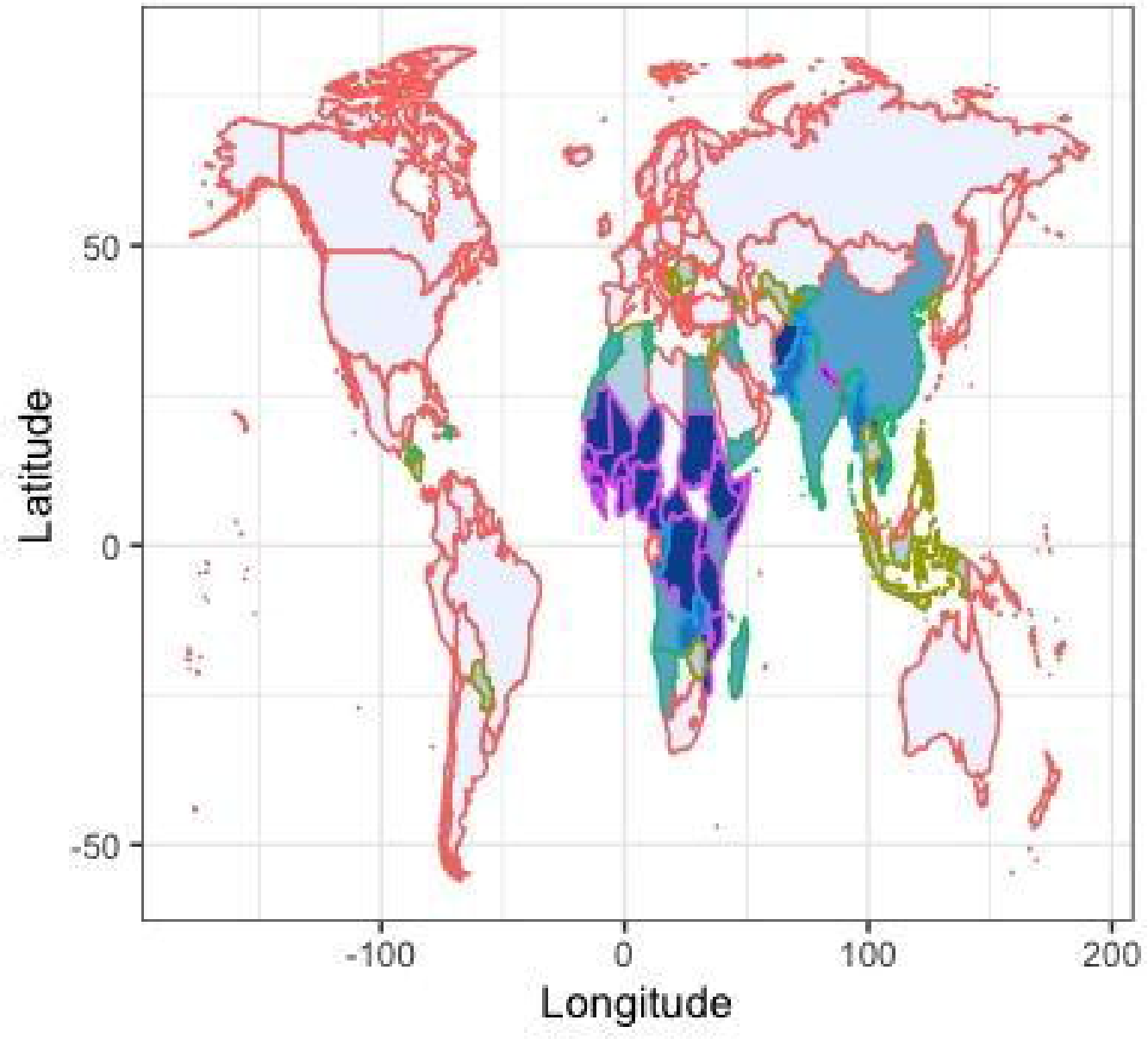

(c) Annual change in PC from 2000 to 2016

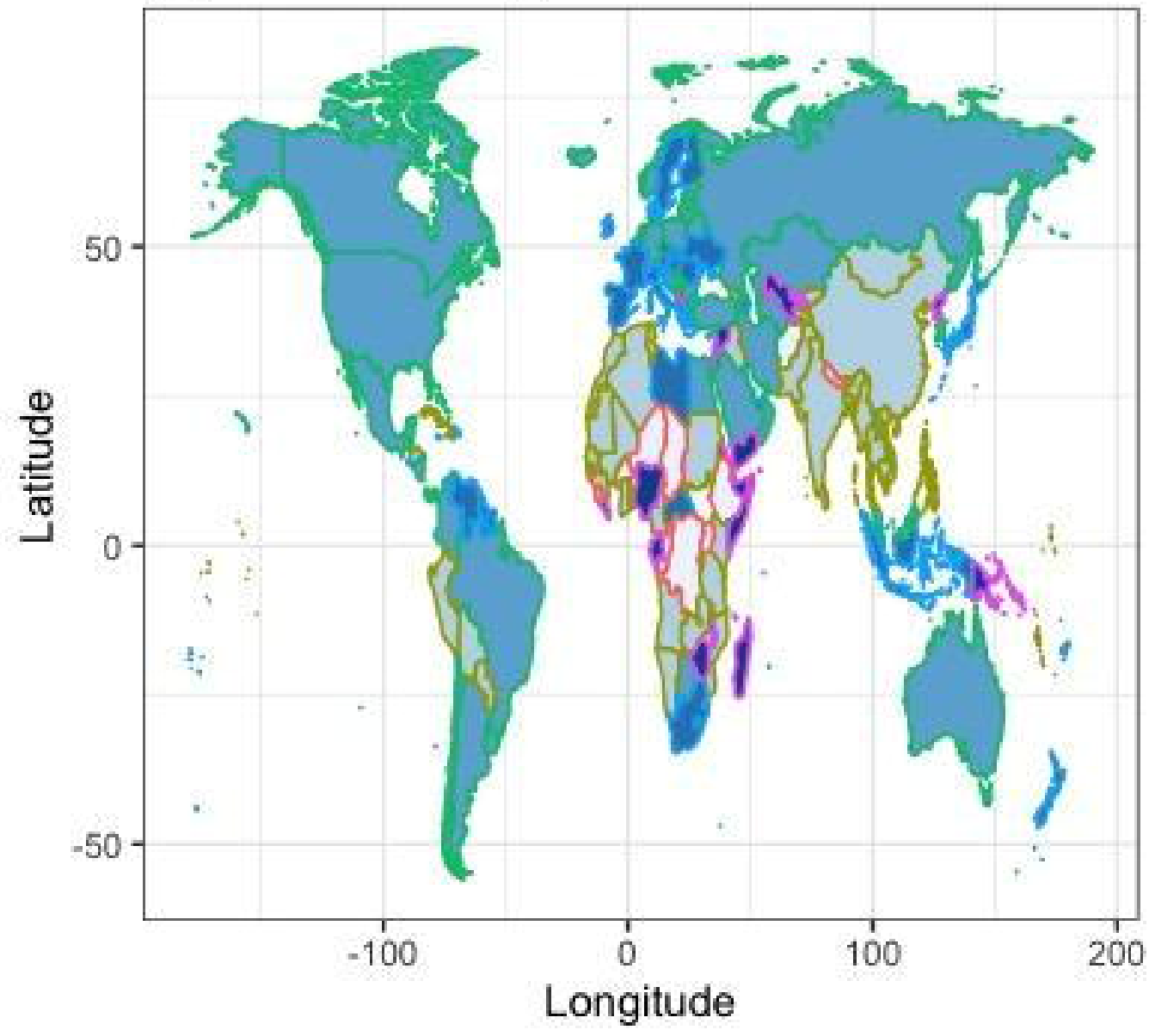

PC

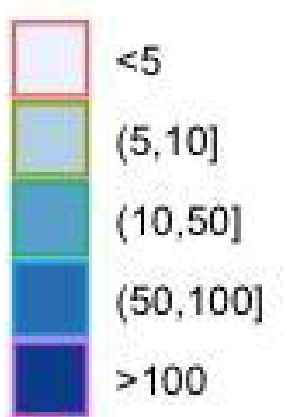

PCchange

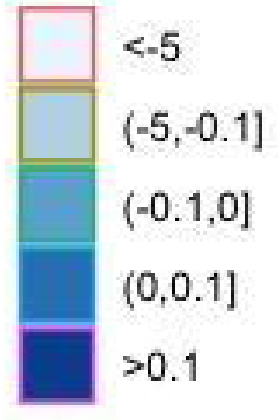

(b) PC of 2016

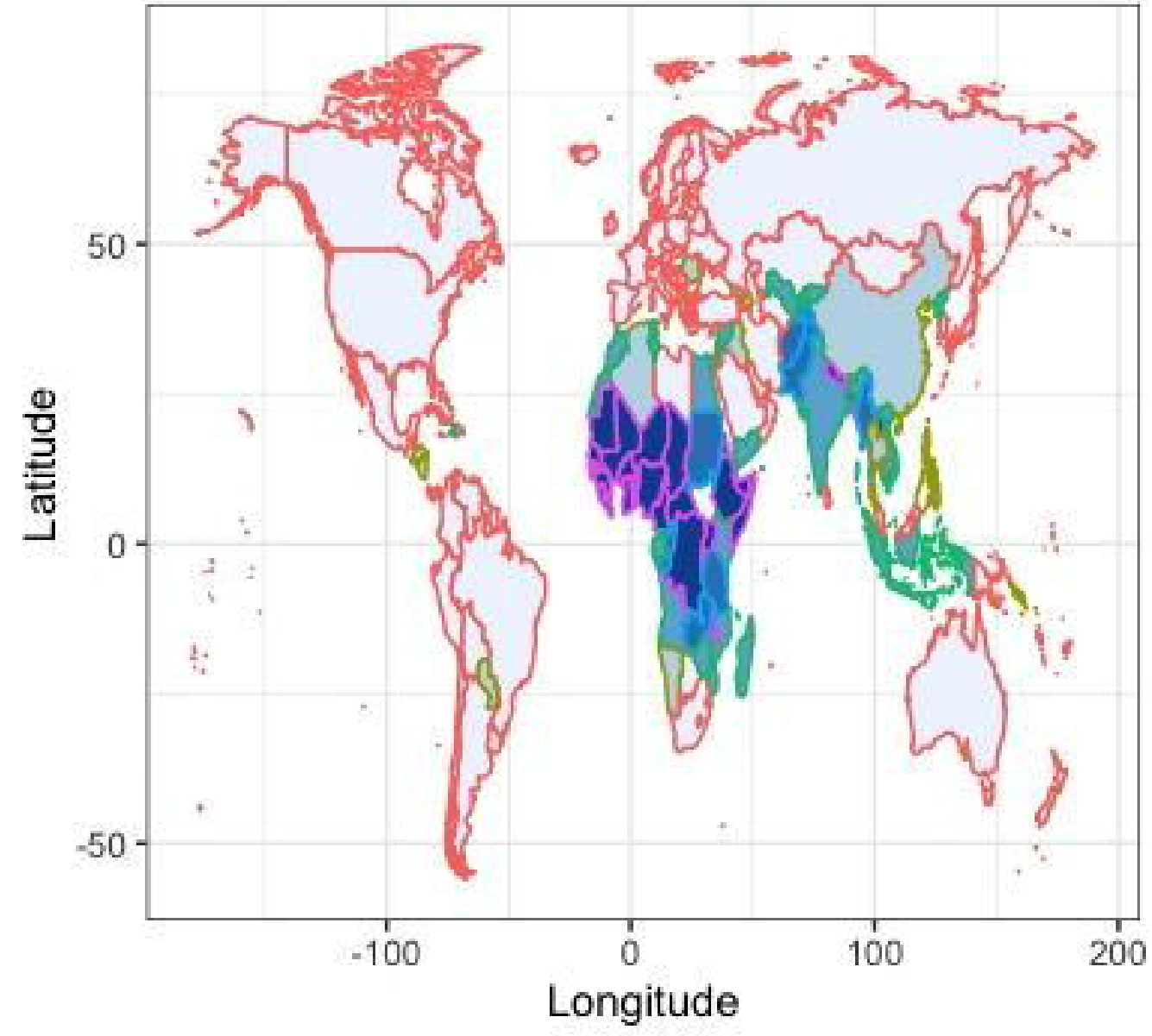

PC $<5$ $(5,10]$ $(10,50]$ $(50,100]$ $>100$ 
